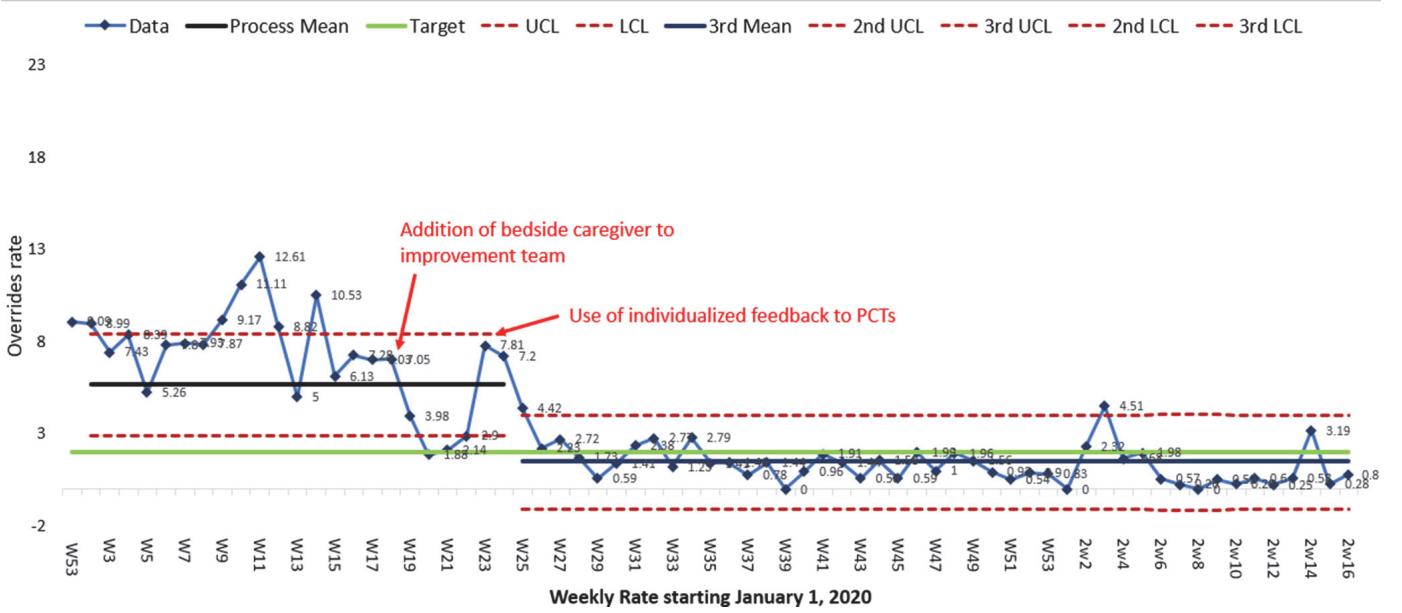

Abstract 9 Figure 2 Imaging - medication overrides

\begin{tabular}{|c|c|c|c|c|c|c|}
\hline \multirow{2}{*}{$\begin{array}{l}\text { Primary Children's Hospital - Failure Mode and Effect } \\
\text { Analysis } \\
\text { Team Members: } \\
\end{array}$} & \multicolumn{5}{|c|}{$\begin{array}{l}\text { Team Leader: Anya Neidig } \\
\text { Team Facilitator: Mouna Bahsoun }\end{array}$} & \multirow[t]{2}{*}{ Evaluation Due Date: December 2020} \\
\hline & & & & & & \\
\hline Failure Modes & Effects & Severity & Probability & Detection & Hazard Score & $\begin{array}{l}\text { Recommendations or } \\
\text { Actions }\end{array}$ \\
\hline Scanners don't work & & 8 & 7 & 1 & 56 & $\begin{array}{l}\text { Provide education to staff on how to reset scanners: } \\
\text { - How to on every pod } \\
\text { - Train a super user on the unit (HUC) } \\
\text { - Provide extra scanners on pods; keep them charged } \\
\text { - Collaborate with IT to have a contact readily available to troubleshoot on the } \\
\text { unit } \\
\text { - Collaborate with IT to collect data related to scanner shut downs; use data to } \\
\text { make technology recommendations. }\end{array}$ \\
\hline Faded Wristbands/Smeared & & 4 & 7 & 5 & 140 & $\begin{array}{l}\text { Assess for legibility of wristband with off-going nurse during bedside handoff report } \\
\text { and call admitting for new wristband if it is faded/smeared. } \\
\text { Design a redundant plan to make sure wristbands are regularly changed; e.g., } \\
\text { standard day of inpatient days to change wristband. }\end{array}$ \\
\hline Dr. orders Tab but liquid is needed & & 6 & 3 & 8 & 144 & Partner with care transformation to adjust/correct order changes. \\
\hline Absence of Barcode on Meds & & 5 & 3 & 2 & 30 & $\begin{array}{l}\text { Identify } 10 \text { most overridden meds (without barcode) and communicate it every } \\
\text { month to pharmacy (Sabrina) who will be adding meds barcode in the system. }\end{array}$ \\
\hline Meds set up under a different FIN & & 7 & 3 & 6 & 126 & $\begin{array}{l}\text { For chemo orders and transfers from NTU to rehab: } \\
\text { - Merge fins } \\
\text { Design a standardized educational process to new hires within admission to follow } \\
\text { process that has been established by Laura Nicolas. }\end{array}$ \\
\hline Position of Barcode on label & & 5 & 1 & 1 & 5 & Call pharmacy to bring a new label and verify correct med, dose, route, patient \\
\hline $\begin{array}{l}\text { No scanning of controlled substance/double checks } \\
\qquad \mathrm{MRI}\end{array}$ & & 9 & 4 & 5 & 180 & $\begin{array}{l}\text { Redesign workflow; create redundant process. } \\
\text { Create a priority list of caregivers to contact when double checks are needed. }\end{array}$ \\
\hline
\end{tabular}

Abstract 9 Figure 3 Primary children's hospital - failure mode and effect

interprofessional team of nurses, physicians, pharmacists, respiratory therapists, imaging techs and quality professionals. The team came together to conduct a Failure Mode and Effects Analysis (FMEA) and identify units with overrides rates above $2 \%$ to build a task force (figure 3). A nurse manager was identified as the task force leader and every unit was represented by a leader and a worker at the point of care. The task force prioritized addressing knowledge, attitudes and behaviors towards BCMA and applied change concepts to engage the workforce in using the technology. This priority was backed up by availability of weekly data that allowed drilling down to individual measurement of medications administered and BCMA use. Continuous improvement was tracked through run charts that displayed organizational and unit-level results starting with pre-interventions baseline data.

Results A sustained BCMA overrides rate below 2\% was achieved, with a mean of 1.26 (figures 1 and 2).

Conclusions When introducing an interprofessional team to proactive risk assessment and continuous improvement, the
IHI's QI Essentials Toolkit proved effective in providing the team with tools to prioritize efforts, test change, achieve results and sustain improvement over time, all while supporting organizational learning.

\section{CIVIC ENGAGEMENT AS A MEANS TO IMPROVE HEALTH EQUITY}

${ }^{1}$ Aliya Bhatia, ${ }^{2}$ Alister Martin, ${ }^{1}$ Rose Teszler. ${ }^{1}$ Vot-ER; ${ }^{2}$ Massachusetts General Hospital

10.1136/bmjoq-2021-IHI.10

Background Patients' socio-economic, political, and environmental contexts are shaped by public policy. Inequitable public policy creates contexts that lead to poor health. Evidence indicates that those who bear the brunt of health inequities are also most likely to be excluded from the democratic process. Healthcare providers' proximity to marginalized patients and 
status as trusted messengers creates favorable conditions for them to participate in non-partisan civic engagement.

Objectives To provide the background, tools, and support necessary for healthcare providers to address the social drivers of poor health by asking patients about their voter registration status.

Methods

- Vot-ER developed the Healthy Democracy Kit (HDK) in 2020 to adapt to the COVID pandemic's added barriers to traditional voter registration

- Health care workers and medical students were recruited via institutional and professional listservs

- Participants were prompted to watch an instructional video emphasizing that all conversations about voter registration must be nonpartisan, voluntary, and sensitive to voter eligibility requirements

Results

- Over 500 hospitals and clinics plus 25,000 healthcare providers use Vot-ER's tools

- 240+ organizations celebrate August as Civic Health Month

- Surveyed providers report increased knowledge of links between civic participation and health, improved well-being, and greater civic engagement

Conclusions Vot-ER's work over the past 18 months serves as a "proof of concept" that hospitals/clinics are ready to take on the role they're authorized to have under the 1993 National Voter Registration Act.

\section{GETTING IT RIGHT, RIGHT NOW, WHILE BUILDING SERVICES READY FOR FUTURE HEALTH NEEDS OF POPULATIONS}

${ }^{1}$ Diana Beveridge, ${ }^{2}$ Susan Hannah, ${ }^{3}$ Robert Kahn, ${ }^{4}$ Anette Nilsson. ${ }^{1}$ Scottish Government; ${ }^{2}$ Institute for Healthcare Improvement; ${ }^{3}$ Cincinnati Children's Hospital; ${ }^{4}$ Region Jonkoping County

10.1136/bmjoq-2021-|HI.11
Background Improving wellbeing outcomes of children has been a joint focus of work for three of IHI's strategic partners in recent years. They are benefitting from collaborating to support the acceleration of work that they have in common and working to close the equity related gap for children and young people in each of their localities. Although each locality is unique, these partners have found the collaboration of learning powerful for each context, and that they have more in common than sets them apart.

Objectives These large scale efforts are ambitious and focused; identifying the children who require support; identifying interventions that will deliver improved outcomes; working collaboratively across sectors and professional groups to provide services that work for the community; and applying a rigorous improvement method to support implementation of change.

Methods Service redesign approaches; co-production with children and community members; multi - disciplinary working across boundaries; the science of improvement to test, measure and implement changes.

Results Achieving high impact results at scale is the ambition of these partners, however, with the knowledge that population health outcomes are generational and can take many years to realise their full potential; these 3 partners describe impactful work on localities with smaller groups, iteratively learning for scalable work. In early years development, in schools and community centers, qualitative and quantitative data describes the journey that these partners are travelling (figures 1-5). It is a story of improvement science in practice and service redesign modelling with children and young people at the center of all they do.

Conclusions These ambitious Strategic Partners have benefitted from a collaborative and virtual learning environment where the exploration and sharing of methods, theories, evidence and practice has supported this global enquiry into child wellbeing, equity and equality issues for disadvantaged communities, and the application of improvement science methods to accelerate change today and for the future.

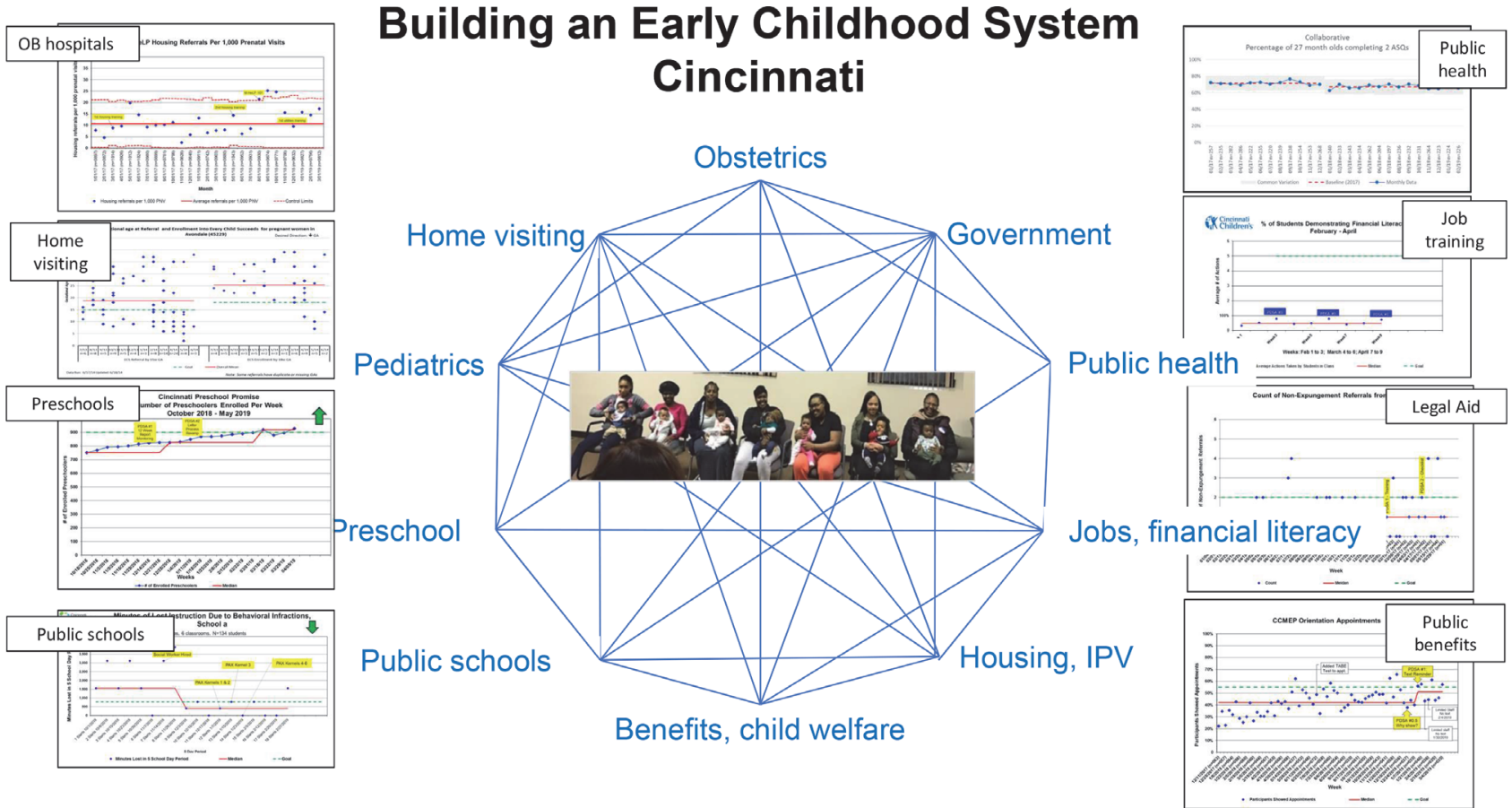

